\title{
Apatinib Inhibits Angiogenesis Via Suppressing Akt/GSK3ß/ANG Signaling Pathway in Anaplastic Thyroid Cancer
}

\author{
Zhijian Jinn Xi Cheng ${ }^{a, b} \quad$ Haoran Feng ${ }^{a, b}$ Jie Kuang ${ }^{a, b}$ Weiping Yang ${ }^{a, b}$ \\ Chenghong Peng ${ }^{a, b} \quad$ Baiyong Shen ${ }^{a, b}$ Weihua Qiu ${ }^{a, b}$ \\ aDepartment of General Surgery, Ruijin Hospital, Shanghai Jiao Tong University School of Medicine, \\ Shanghai, 'bShanghai Institute of Digestive Surgery, Ruijin Hospital, Shanghai Jiao Tong University \\ School of Medicine, Shanghai, China
}

\section{Key Words}

Apatinib • Angiogenin • Agiogenesis • Akt $•$ GSK3 $\beta$ Anaplastic thyroid carcinoma

\begin{abstract}
Background/Aims: Anaplastic thyroid carcinoma (ATC) is one of the most lethal human malignancies, and there is no efficient method to slow its process. Apatinib, a novel tyrosine kinase inhibitor (TKI), has been confirmed for its efficacy and safety in the treatment of advanced gastric carcinoma patients. However, the effects of Apatinib in ATC are still unknown. Methods: In this study, we explored the effects and mechanisms of Apatinib on tumor growth and angiogenesis in vitro and in vivo in ATC cells. Angiogenesis antibodies array was utilized to detect the expression of angiogenesis-related genes after Apatinib treatment in ATC cells. In addition, we used Akt activator, Akt inhibitor and GSK3 $\beta$ inhibitor to further study the mechanism for how Apatinib suppressed angiogenesis. Results: Apatinib treatment could suppress the growth of ATC cells in a dose- and time-dependent manner via inducing apoptosis and blocking cell cycle progression at G0/G1 phase. Moreover, Apatinib treatment decreased the expression of angiogenin (ANG) and inhibited angiogenesis of ATC cells in vitro and in vivo. We further confirmed that recombinant human ANG (rhANG) significantly abrogated Apatinib-mediated anti-angiogenic ability in ATC cells. Additionally, Apatinib treatment decreased the level of p-Akt and p-GSK3 3 . Moreover, the Apatinib-mediated decrease of ANG and anti-angiogenic ability were partly reversed when an Akt activator, SC79, was administered. Furthermore, the anti-angiogenic ability of Apatinib can be enhanced in the presence of Akt inhibitor, and the inhibition of GSK3 $\beta$ attenuated the anti-angiogenic ability of Apatinib. Conclusion: Our results demonstrated that Apatinib treatment inhibited tumor growth, and Apatinib-induced suppression of Akt/GSK3B/ANG signaling pathway may play an important role in the inhibition of angiogenesis in ATC, supporting a potential therapeutic approach for using Apatinib in the treatment of ATC.

Z. Jin, X. Cheng and H. Feng contributed equally to this work.

\begin{tabular}{ll}
\hline Chenghong Peng, Baiyong Shen & Department of Surgery, Shanghai Institute of Digestive Surgery, Ruijin Hospital, \\
and Weihua Qiu & Shanghai Jiao Tong University School of Medicine, Shanghai, (China) \\
& E-Mail pchccr@163.com, sbyccr@163.com, drqwh2003@126.com
\end{tabular}




\section{Cellular Physiology Cell Physiol Biochem 2017;44:1471-1484 \begin{tabular}{l|l} 
and Biochemistry Published online: Dezember 01, 2017 & $\begin{array}{l}\text { O 2017 The Author(s). Published by S. Karger AG, Basel } \\
\text { www.karger.com/cpb }\end{array}$
\end{tabular} \\ Jin et al.: Apatinib Inhibits Angiogenesis in Anaplastic Thyroid Cancer}

\section{Introduction}

Anaplastic thyroid carcinoma (ATC) is one of the most lethal human malignant tumors, characterized as high levels of rapid proliferation, extrathyroidal invasion, and distant metastasis. More importantly, unlike differentiated thyroid carcinoma, ATC has been proved to be resistant to conventional treatment, including surgical, chemical, isotopic interventions $[1,2]$. Therefore, ATC is the major cause of all thyroid carcinoma-related deaths, with a median survival of 3-9 months and a 20\% 1-year survival rate [3, 4]. 90\% of patients with ATC have extraglandular spread at the time of diagnosis, and $75 \%$ of the patients will develop distant metastasis during their disease course [5]. Neovascularization is necessary for ATC growth and dissemination $[3,6]$.

Angiogenin (ANG) is a 14.2-kDa secreted single chain basic protein composed of 123 amino acids [7]. ANG has been confirmed to be involved in several stages of angiogenesis in malignant carcinoma via its multi-functional effects in signaling pathway networks [8], which also could apparently enhance angiogenesis of ATC in our primary study.

Apatinib, a novel tyrosine kinase inhibitor (TKI), can inhibit multiple tumor related kinases, such as vascular endothelial growth factor receptor-2 (VEGFR-2), rearranged during transfection (RET), platelet-derived growth factor- $\beta$ (PDGFR- $\beta$ ), stem cell factor receptor (c-Kit), and v-Src sarcoma viral oncogene homolog (c-Src) [9]. Apatinib has highly selective competition in the ATP binding site of VEGFR-2, then blocking downstream signaling pathways and inhibiting tumor angiogenesis [10]. Considering apparent neovascularization in ATC, in this study, we explored the role of Apatinib in cytotoxicity and angiogenesis of ATC. Our results showed that Apatinib could efficiently inhibit ATC cells growth via inducing both apoptosis and cell cycle arrest. Furthermore, Apatinib-induced angiogenesis inhibition in ATC cells was mediated by regulation of Akt/GSK3 $\beta /$ ANG signaling pathway. These findings launched a new insight that Apatinib can be further studied as a potential agent for ATC treatments.

\section{Materials and Methods}

\section{Cell Culture and Reagents}

Human ATC cell lines CAL-62, BHT-101, HTh-7, KHM-5M, BHT-101 and 8305C were obtained from China Center for Type Culture Collection (CCTCC, Wuhan, China). CAL-62, HTh-7, BHT-101 and 8305C cells were cultured in DMEM medium with 10\% fetal bovine serum (Gibco, USA); C643 and KHM-5M cells were maintained in RPMI-1640 medium with the same components [11-13]. All cells incubated at $37^{\circ} \mathrm{C}$ and $5 \%$ CO2 (Shanghai Medical Instruments, China). Apatinib was obtained from Hengrui Medicine Co. Ltd. (Jiangsu, China), then dissolved in DMSO and diluted with DMEM or 1640 medium to achieve a desired concentration for vitro experiments. Apatinib was dissolved in CMC for vivo experiments. Prior to each treatment, cells were plated overnight and were in similar subconfluent density at the time of drug exposure. SC79, API-2 and LiCl were purchased from Sigma-Aldrich Chemical Company (St. Louis, MO, USA).

\section{CCK-8 Assays of Cell Viability and Colony Formation Assay}

The cytotoxicity of Apatinib was estimated using the CCK-8 assay (Cell Counting Kit-8, Dojindo, Kumamoto, Japan). Cells were plated in 96-well plates at 3, 000 cells per well $24 \mathrm{~h}$ before treatment. The cells were then treated with Apatinib at $0.5,1,5,10,20,40$ and $80 \mu \mathrm{M}$ for 24,48 , or $72 \mathrm{~h}$, respectively. DMSO was added to cultures as a solvent control. For the colony formation assay, 1, 000 cells were plated in 6-well plate and cultured at $37^{\circ} \mathrm{C}$ for 14 days. The colonies were observed by staining with $0.1 \%$ crystal violet in methanol for $30 \mathrm{~min}$. For the colony formation in soft agar, 1000 cells suspended in $0.7 \%$ soft agar were plated on the surface of $1.2 \%$ soft agar in 6 -well plate and cultured at $37^{\circ} \mathrm{C}$ for 2 weeks.

Apoptosis Detection and Cell Cycle Analyses

Flow cytometric assays of apoptosis and cell cycle were performed as previously described [14]. Briefly, cells were treated with 5 or $10 \mu \mathrm{M}$ Apatinib for $24 \mathrm{~h}$. Then both attached and the floating cells were 


\section{Cellular Physiology Cell Physiol Biochem 2017;44:1471-1484 \begin{tabular}{ll|l}
\cline { 2 - 3 } DOI: 10.1159/000485583 & () 2017 The Author(s). Published by S. Karger AG, Basel
\end{tabular} and Biochemistry Published online: Dezember 01, 2017 www.karger.com/cpb \\ Jin et al.: Apatinib Inhibits Angiogenesis in Anaplastic Thyroid Cancer}

harvested, washed twice with ice-cold PBS and suspended in $100 \mu \mathrm{l}$ binding buffer. Cells were incubated with $3 \mu \mathrm{l}$ FITC-Annexin V and $5 \mu \mathrm{l}$ PI at room temperature for 15 minutes in the dark. Next we added an additional $300 \mu \mathrm{l} 1 \times$ Binding Buffer to each sample. The cells were harvested and suspended in ice-cold PBS after treatment for cell cycle distribution analysis. Single-cell suspensions were fixed with $70 \%$ cold ethanol at $4^{\circ} \mathrm{C}$ overnight. Afterwards samples were washed twice with cold PBS and incubated with PI (50 $\left.\mu \mathrm{g} / \mathrm{ml}\right)$ for $30 \mathrm{~min}$ in the dark, then analyzed by flow cytometer.

\section{Endothelial Tube Formation Assay}

HUVEC cells were cultured in tumor supernatant and plated in 96-well plate coated with $50 \mu \mathrm{l}$ matrigel (BD Bioscience, CA, USA), approximately $1 \times 10^{4}$ per well. Tumor supernatant was collected from both control groups and Apatinib treatment groups cultured after $24 \mathrm{~h}$. After $6 \mathrm{~h}$ of incubation at $37^{\circ} \mathrm{C}$ with $5 \%$ CO2, tubules were photographed by microscopy and evaluated by Image Pro Plus software.

\section{Western blot analysis}

After treatment, cells were harvested and digested in RIPA buffer with the presence of Protease Inhibitor Cocktail (Pierce, USA), and protein concentration was quantified using the BCA Assays (Thermo Scientific). After electrophoresis in SDS-PAGE and transfering to PVDF membranes (Bio-Rad, Hercules, CA), proteins were then incubated with primary and secondary antibodies. The primary antibodies were listed as follows: ANG, AKT, p-AKT, GSK3 $\beta$, p-GSK3 $\beta$ Ser9, GAPDH.

\section{Angiogenesis antibody array}

The samples from CAL-62/control and CAL-62/Apatinib $(10 \mu \mathrm{M})$ groups were collected for human angiogenesis array analysis. The levels of 43 angiogenesis-associated proteins were analyzed by using the Human Angiogenesis Antibody Array C1000 (RayBiotech, Norcross, Ga) according to the manufacturer's protocol. Fold-change was cut-off at 1.5x; significance testing was performed by t-test.

\section{Quantitative real-time RT-PCR}

ANG mRNA expression was determined by real-time PCR using SYBR Premix Ex Taq (TaKaRa, Japan) as previously described [15]. Primers pairs utilized were following: ANG: 5'- CTGGGCGTTTTGTTGTTGGTC-3' and 5'- GGTTTGGCATCATAGTGCTGG-3'; GAPDH: 5'- CATGAGAAGTATGACAACAGCCT-3' and 5' -AGTCCTTCCACGATACCAAAGT-3'.

\section{Chick Embryo Chorioallantoic Membrane (CAM) Assay}

Fertilized chicken eggs (Xing-Huo farm, Shanghai, China) were incubated at $37^{\circ} \mathrm{C}$ in a $70 \%$ humidified environment. On the 6th day, an opening was punctured on the shell and was sealed with transparent tape. Next day, a piece of sterilized filter paper disk $(0.5 \mathrm{~cm}$ diameter $)$ was placed on the surface of the CAM. 30- $\mu$ l supernatant from CAL-62 and CAL-62/Apatinib $(10 \mu \mathrm{M})$ was dropped onto the filter paper disk and sealed with transparent tape for the next consecutive 3 days. On the 10th day, the eggs were photographed with MacroPATH dissecting microscope (Milestone, Italy) and the number of blood vessels around the filter paper disc was assessed.

\section{Xenograft Tumor Model, Immunohistochemistry and TUNEL Assay}

Four-week-old male BALB/c nude mice were purchased from the Institute of Zoology, Chinese Academy of Sciences of Shanghai. Approximately $5 \times 10^{6}$ CAL- 62 cells were injected into the right flank of nude mice. Two weeks after inoculation, the mice were randomly divided into either the Apatinib treatment or control group ( $\mathrm{N}=5$ per group). Mice were administered a daily oral gavage with $50 \mathrm{mg} / \mathrm{kg}$ Apatinib or vehicle-only solution.

Tumor dimensions were measured using a Vernier caliper, and the tumor volume was calculated using the following formula: $\mathrm{V}=\pi / 6$ (length) $\times($ Width $) \times($ Width $) / 2$ Tumor size were measured every 3 days. Three days after the last treatment, the animals were euthanized by cervical decapitation and tumors were removed and weighed. Tumor dimensions were measured using a Vernier caliper, and the tumor volume was calculated using the following formula: $V=($ length $) \times($ Width $) \times($ Width $) / 2$. The immunohistochemistry of xenograft tumor in nude mice was conducted as previously described [16]. Slides were incubated by antibodies including Ki-67 (1:100, Abcam) CD31 (1:200, Santa Cruz) and ANG (1:200, Santa Cruz). The 


\section{Cellular Physiology Cell Physiol Biochem 2017;44:1471-1484

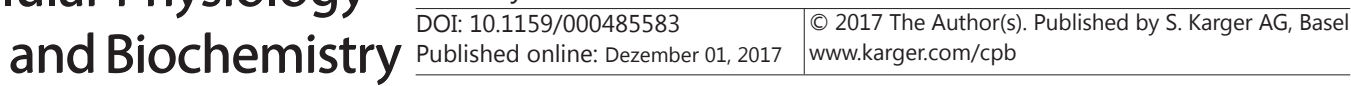 \\ Jin et al.: Apatinib Inhibits Angiogenesis in Anaplastic Thyroid Cancer}

apoptotic cells were detected by the TUNEL assay using In Situ Cell Death Detection Kit, Fluorescein (Roche Applied Science, USA) according to the manufacturer's protocol and nuclei were detected by DAPI staining.

\section{Statistical Analysis}

Data is expressed as the means \pm SD. An analysis of variance (ANOVA) and Student's test were used for comparison among groups. The Mann-Whitney U test was used for comparison of tumor volume. Categorical data is evaluated with the chi-square test or Fisher exact test. A $P$-value less than 0.05 was considered to be significant.
Table 1. $\mathrm{IC}_{50}$ values of Apatinib in various ATC cell lines. $\mathrm{IC}_{50}, 50 \%$ inhibitory concentration; ATC, anaplastic thyroid carcinoma

\begin{tabular}{lccc}
\hline \multirow{2}{*}{ Cell lines } & \multicolumn{3}{c}{ IC50 $(\mu \mathrm{M})$} \\
& $24 \mathrm{~h}$ & $48 \mathrm{~h}$ & $72 \mathrm{~h}$ \\
\hline CAL-62 & 68.44 & 38.64 & 16.47 \\
C643 & 62.68 & 25.32 & 11.02 \\
KHM-5M & 70.83 & 37.26 & 17.36 \\
HTh-7 & $>80$ & 41.26 & 22.11 \\
BHT-101 & 59.45 & 15.11 & 10.93 \\
8305C & 64.65 & 24.23 & 17.28 \\
\hline
\end{tabular}

\section{Results}

Apatinib inhibits ATC cells proliferation

To analyze the effects of Apatinib on the proliferation of ATC cell lines, ATC cells were treated with a series of concentrations of Apatinib for 24 h, 48 h and 72 h, respectively. Apatinib performed a dose- and time-dependent manner in inhibiting the cell viability (Fig. 1A). The $\mathrm{IC}_{50}$ values for six ATC cell lines with Apatinib for $24 \mathrm{~h}, 48 \mathrm{~h}$ and $72 \mathrm{~h}$ were shown in Table 1. Contact-dependent growth assay by cloning formation was performed to further confirm the effect of Apatinib on inhibiting ATC cells proliferation. We observed the fewer clone number in CAL-62 and BHT-101 cells after Apatinib treatment (Fig.1B and 1C). 3D growth model in soft agar colony formation also confirmed the effect of Apatinib on proliferation of ATC cells (Fig. 1D and 1E).

\section{Apatinib induces apoptosis in ATC cell lines}

As assessed by flow cytometry, treatment of Apatinib significantly induced apoptosis as compared with the control group in CAL-62 cells and especially in BHT-101 cells (Fig. 2A and 2B). The apoptotic rates were $5.86 \pm 0.29 \%$ and $13.31 \pm 0.46 \%$ in CAL-62 and BHT-101 cells respectively after $10 \mu \mathrm{M}$ of Apatinib treatment, which were remarkably higher than those in the control group (CAL-62: $5.86 \pm 0.29 \%$ vs $2.23 \pm 0.24 \%, p<0.05$; and BHT-101: $13.31 \pm$ $0.46 \%$ vs $3.93 \pm 0.28 \%, p<0.05)$. In addition, the apoptotic rate increased with respect to the concentrations of Apatinib. Thus, our data demonstrated that Apatinib induced apoptosis in ATC cell lines in a dose-dependent manner.

\section{Apatinib blocks cell cycle in ATC cell lines}

We next detected cell cycle progression in CAL-62 and BHT-101 cells after Apatinib treatment by flow cytometry. The percentage of the $\mathrm{S}$ phase proportion decreased conspicuously and G0/G1 phase increased after Apatinib treatment both in CAL-62 and BHT101 cells (CAL-62: $16.43 \pm 1.10 \%$ (10 $\mu \mathrm{M}$ Apatinib) vs $32.57 \pm 2.09 \%$ (control), $p<0.05$; and BHT-101: $9.74 \pm 1.16 \%$ (10 $\mu \mathrm{M}$ Apatinib) vs 30.91 $\pm 2.08 \%$ (control), $p<0.05$, Fig. $2 \mathrm{C}$ and 2D). This data indicated that Apatinib could markedly inhibit G1-S transition in ATC cell lines. Thus, our results herein illustrated that Apatinib may function as an antitumor drug by inhibiting proliferation of cancer cells.

\section{Apatinib inhibits HUVEC cell migration and tubular formation of HUVEC cells}

CAL-62 and BHT-101 cells treated with 5 or $10 \mu \mathrm{M}$ of Apatinib for 24 h. To culture HUVEC cells, tumor supernatant was collected from CAL-62/Apatinib ( $5 \mu \mathrm{M})$, CAL-62/Apatinib $(10 \mu \mathrm{M})$, BHT-101/Apatinib $(5 \mu \mathrm{M})$, BHT-101/Apatinib $(10 \mu \mathrm{M})$ and their corresponding control groups. $1 \times 10^{5}$ HUVEC cells were plated into the upper chamber of transwell coated with or without matrigel; incubated for $24 \mathrm{~h}$ at $37^{\circ} \mathrm{C}$ with $5 \% \mathrm{CO}_{2}$. With Apatinib concentra- 


\section{Cellular Physiology Cell Physiol Biochem 2017;44:1471-1484 \begin{tabular}{l|l|l} 
DOI: 10.1159/000485583 & () 2017 The Author(s). Published by S. Karger AG, Basel
\end{tabular} Jin et al.: Apatinib Inhibits Angiogenesis in Anaplastic Thyroid Cancer}

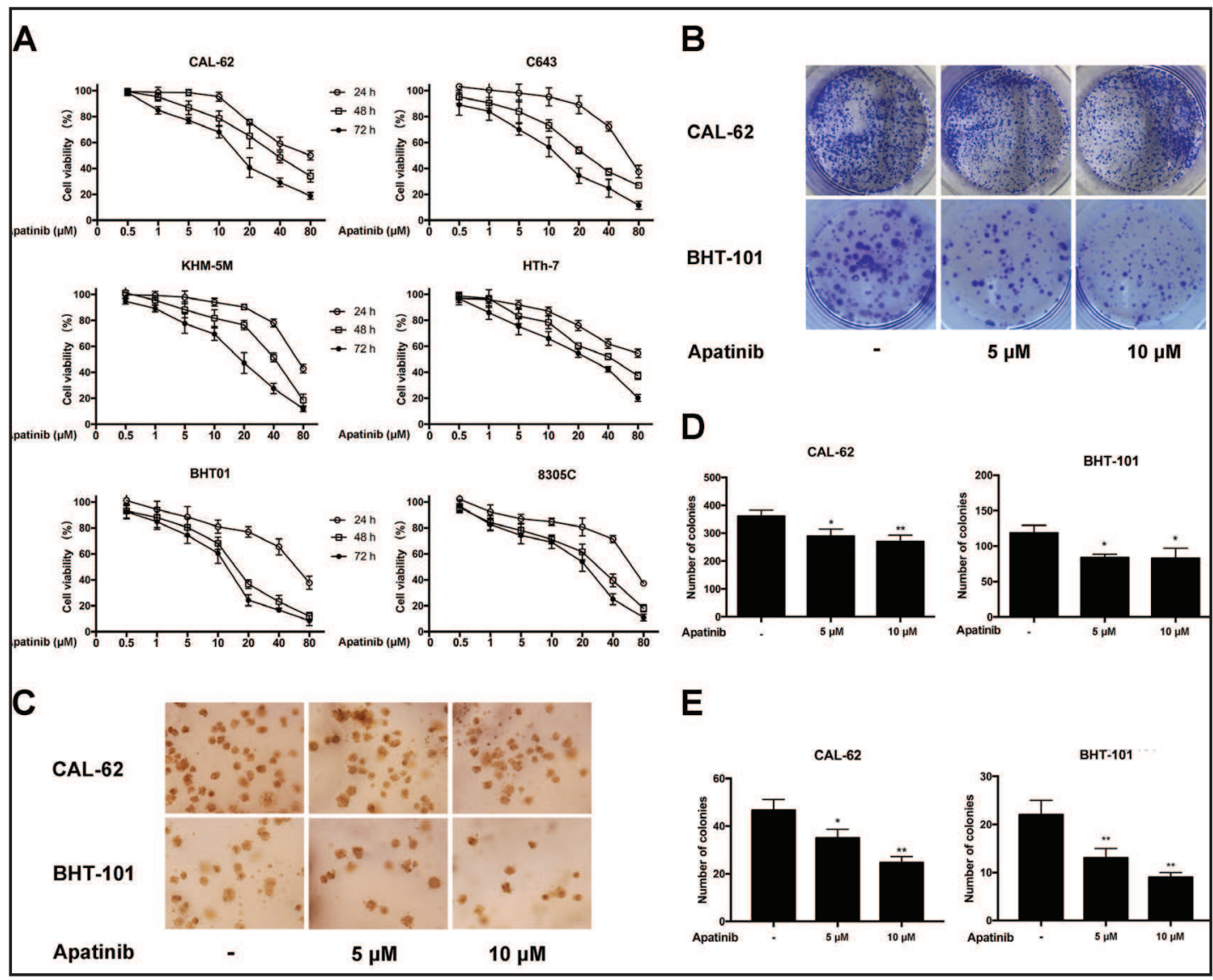

Fig. 1. The effects of Apatinib on cell proliferation. (A) Cells were cultured in control conditions (DMSO) or in the present of a series of concentration of Apatinib for $24 \mathrm{~h}, 48 \mathrm{~h}$ and $72 \mathrm{~h}$. Cell viability was assessed by CCK-8 assay. The data are averages of triplicate results from representative experiments. (B) Representative images of contact-dependent clone formation. (C) The columns represent the mean \pm SD of the three independent experiments. (D) Representative images of clone formation in soft agar. (E) Data represent the mean \pm SD and are representative of three independent experiments. ${ }^{*} \mathrm{p}<0.05,{ }^{* *} \mathrm{p}<0.01$, compared with control group.

tion increasing, the migration ability of HUVEC cells was gradually reduced both in CAL-62 and BHT-101 cells (Fig. 3A and 3B). A similar tendency was observed in the invasive ability of HUVEC cells (Fig. 3C and 3D). meanwhile, $1 \times 10^{4}$ HUVEC cells were plated into 96-well plate coated with matrigel and incubated for $4 \mathrm{~h}$ at $37^{\circ} \mathrm{C}$ with $5 \% \mathrm{CO}_{2}$. We observed less tubular formation in Apatinib treatment groups compared with the control groups (Fig.3E and 3F). Thus, these results suggested that Apatinib inhibited tumor angiogenesis in ATC by inhibiting HUVEC migration, invasion, and tubular formation.

Apatinib represses the expression of angiogenesis-related genes in ATC cells.

To investigate the mechanisms involved in Apatinib inhibition of angiogenesis, we used Angiogenesis antibody array to detect the expression of angiogenesis-related genes after Apatinib treatment $(10 \mu \mathrm{M})$ (Fig. $4 \mathrm{~A}$ and $4 \mathrm{~B})$. Apatinib significantly downregulated the expression of ANG, VEGFR2 and TNF- $\alpha$ in ATC cells (Fig. 4C). These results indicated that the anti-angiogenic effects of Apatinib were executed through a mechanism involving multiple genes. ANG has been recognized as an important angiogenic factor in the development of human malignant tumors. In our study, quantification data showed that ANG protein expression was reduced in a dose-dependent manner after Apatinib treatment (Fig. 4D). Furthermore, Apatinib-mediated anti-angiogenic effect was significantly attenuated in the 

Cellular Physiology Cell Physiol Biochem 2017;44:1471-1484 \begin{tabular}{|l|l|l|l}
\hline DOI: 10.1159/000485583 & 2017 The Author(s). Published by S. Karger AG, Basel \\
\hline
\end{tabular} and Biochemistry Published online: Dezember 01, 2017 www.karger.com/cpb

Fig. 2. Apatinib promotes apoptosis and blocks cell cycle in ATC cells. (A) The ratio of apoptotic cells was measured in CAL-62 and BHT-101 cells after treatment with the indicate concentrations of Apatinib for $24 \mathrm{~h}$. The results were representative of three independent experiments. (B) The percentage of apoptotic cells was investigated using Annexin V-FITC and PI. (AnV+) PI- cells were considered early apoptotic and (AnV+) PI+ cells were considered late apoptotic. The columns represent the mean $\pm \mathrm{SD}$ of the three independent experiments. $\quad * * \mathrm{p}<0.01$, compared with control. (C) CAL-62 and BHT-101 cells were treated with Apatinib in indicate concentration for $24 \mathrm{~h}$. Then cell cycle phase distribution was detected by flow cytometry. The results were representative of three independent experiments. (D) The percentages of cells in G1, S, and G2-M were shown as histograms.
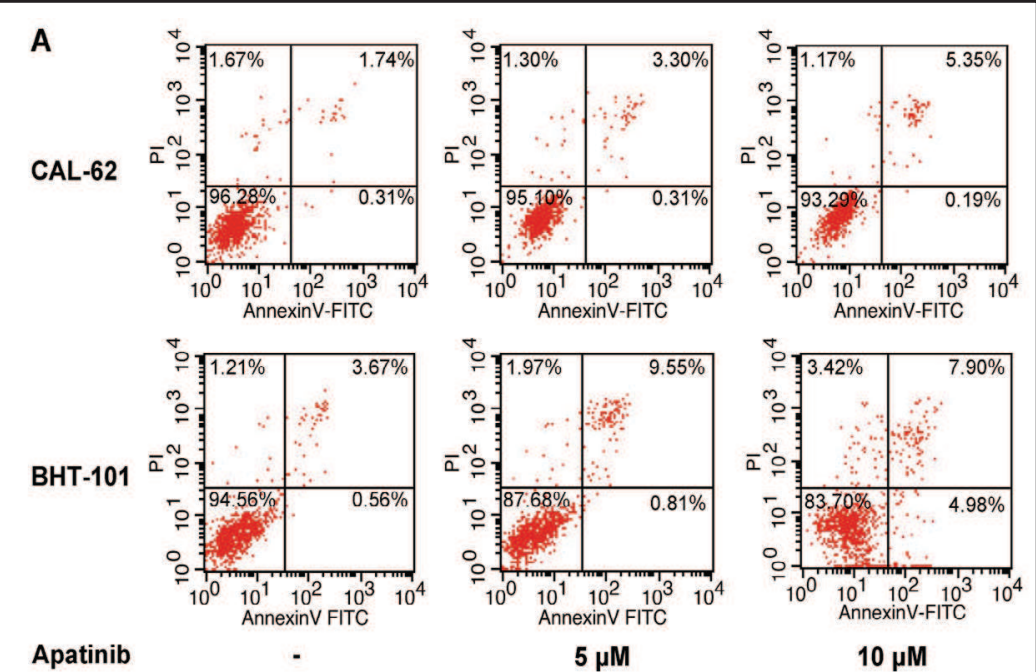

B

CAL-62
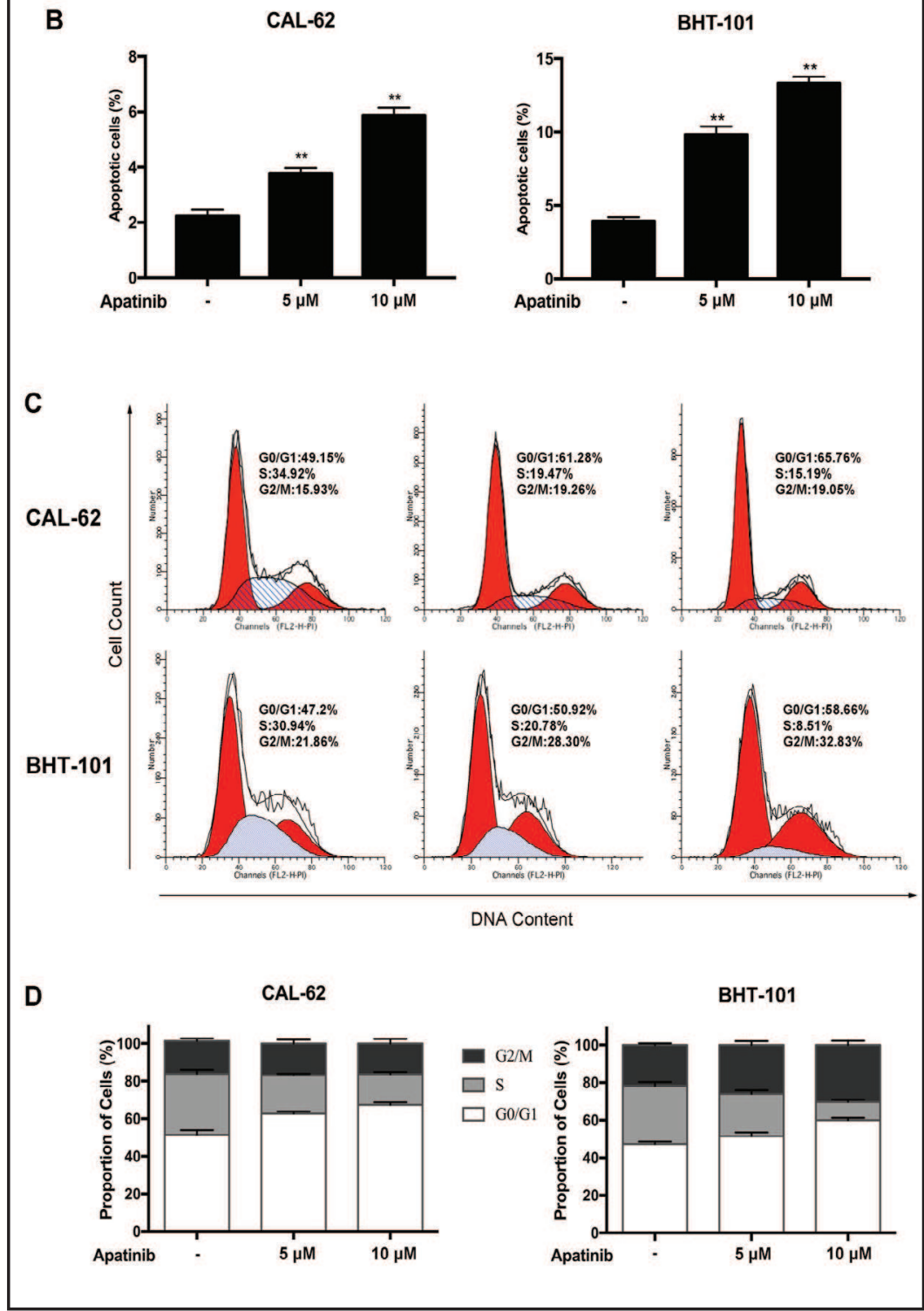


\section{Cellular Physiology Cell Physiol Biochem 2017;44:1471-1484

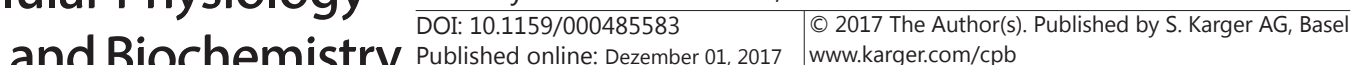

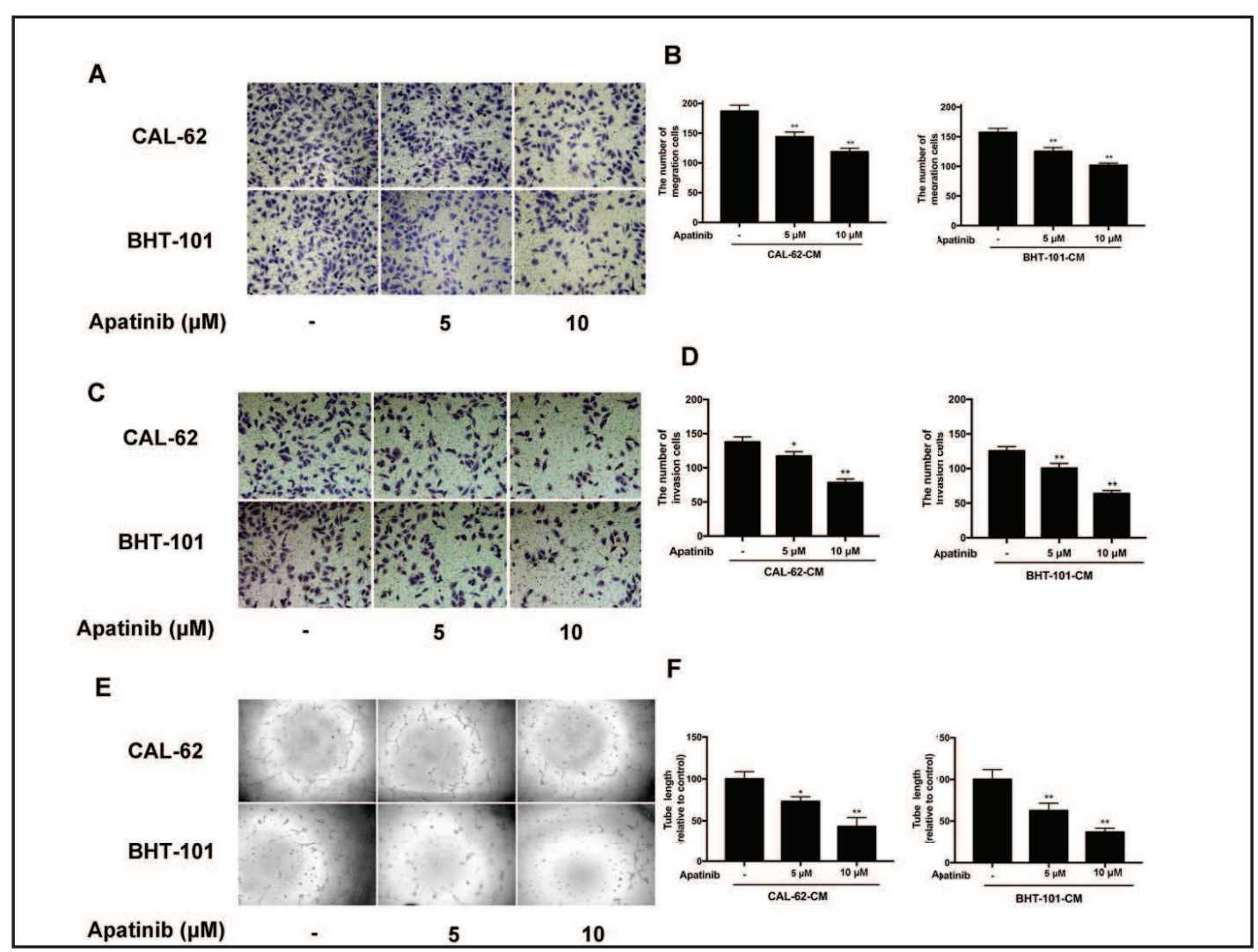

Fig. 3. Effects of Apatinib on migration, invasion and tubular formation of HUVECs. (A) Apatinib treatment inhibited the migration of HUVECs. (B) Histograms showed the numbers of migration cells. Data are represented as mean \pm SD of three independent experiments. (C) Treatment of Apatinib inhibited the invasion of HUVECs. (D) Histograms showed the numbers of invasion cells. (E) Less tubules were observed in the Apatinib treatment groups compared with the control groups. (F) Bar charts showed mean tubular lengths relative to control. Data are represented as mean \pm SD of three independent experiments. ${ }^{*} \mathrm{p}<0.05 ;{ }^{* *} \mathrm{p}<0.01$.

presence of recombinant human ANG (rhANG) treatment (Fig. 4E). All these results showed that ANG could promote angiogenesis and the expression of ANG could be inhibited by Apatinib treatment.

\section{Akt/GSK3 $\beta / A N G$ signaling is involved in the anti-angiogenic effects of Apatinib}

Recent research has shown activated GSK3 $\beta$ can decrease HIF-1 $\alpha$ to inhibit angiogenesis, and GSK3 $\beta$ may be inhibited by AKT via phosphorylation of its Ser9 and Ser21 $[17,18]$. The activity of AKT performs an important role in angiogenesis [19]. Therefore, the level of AKT and GSK3 $\beta$ was examined; and the results showed that the phosphorylation of these proteins decreased in a concentration-dependent manner in response to Apatinib in CAL-62 and BHT-101 cells (Fig. 5A).

To determine whether Akt/GSK3 $\beta$ signaling participates in Apatinib-induced reduction of ANG and angiogenesis, CAL-62 cells were subsequently treated together with Apatinib and SC79 (the activator of Akt). The Apatinib-induced decrease of p-GSK3 $\beta$ and ANG were reversed through the activation of Akt, resulting in a significantly improved angiogenesis (Fig. 5B-D). To further examine the role of Akt in Apatinib-mediated inhibition of angiogenesis, API-2, an inhibitor of Akt, was utilized to deactivate Akt. Deactivation of Akt decreased the level of p-GSK3 $\beta$, ANG and angiogenesis (Fig. 5E-G). Additionally, LiCl, an inhibitor of GSK3 $\beta$, was used to verify that GSK3 $\beta$ was involved in the anti-angiogenic ability of Apatinib. The reduction of Apatinib-mediated ANG and angiogenesis was reversed by LiCl (Fig. 5H-J). 

Cellular Physiology Cell Physiol Biochem 2017;44:1471-1484 \begin{tabular}{l|l|l|l}
\hline DOI: 10.1159/000485583 & O 2017 The Author(s). Published by S. Karger AG, Basel \\
\hline
\end{tabular} and Biochemistry Published online: Dezember 01, 2017 www.karger.com/cpb

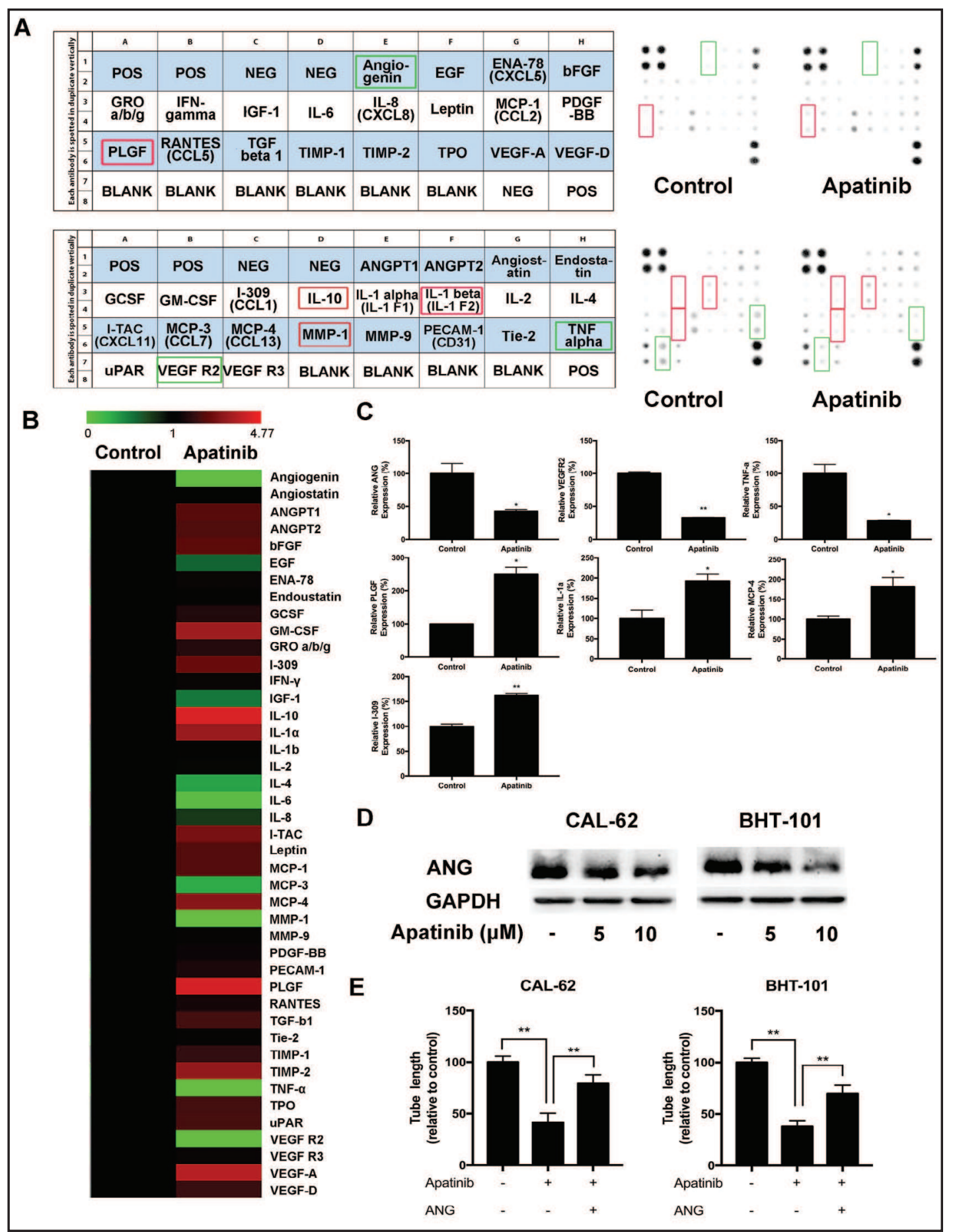

Fig. 4. Apatinib decreases the level of multiple angiogenesis-related protein. (A) Antibody arrays of protein expression of angiogenesis-related genes after Apatinib treatment. (B) The heat map of antibody arrays. Up and down arrows, protein expression significantly upregulated or downregulated, respectively, by 1.5-fold. (C) Analysis of antibody array grey levels. (D) The level of ANG after treatment of Apatinib in ATC cells was assayed by western blotting. (E) HUVEC cells were treated with supernatant from different group for tube formation assay. RhANG significantly enhanced tube formation. ${ }^{*} \mathrm{p}<0.05,{ }^{* *} \mathrm{p}<0.01$.

These results showed that Apatinib may repress ANG production and inhibit angiogenesis by suppressing AKT/GSK3 $\beta$ pathway in ATC cells. 


\section{Cellular Physiology Cell Physiol Biochem 2017;44:1471-1484 \begin{tabular}{l|l|l}
\cline { 2 - 3 } DOI: 10.1159/000485583 & $\odot 2017$ The Author(s). Published by S. Karger AG, Base
\end{tabular} and Biochemistry Published online: Dezember 01, 2017 www.karger.com/cpb

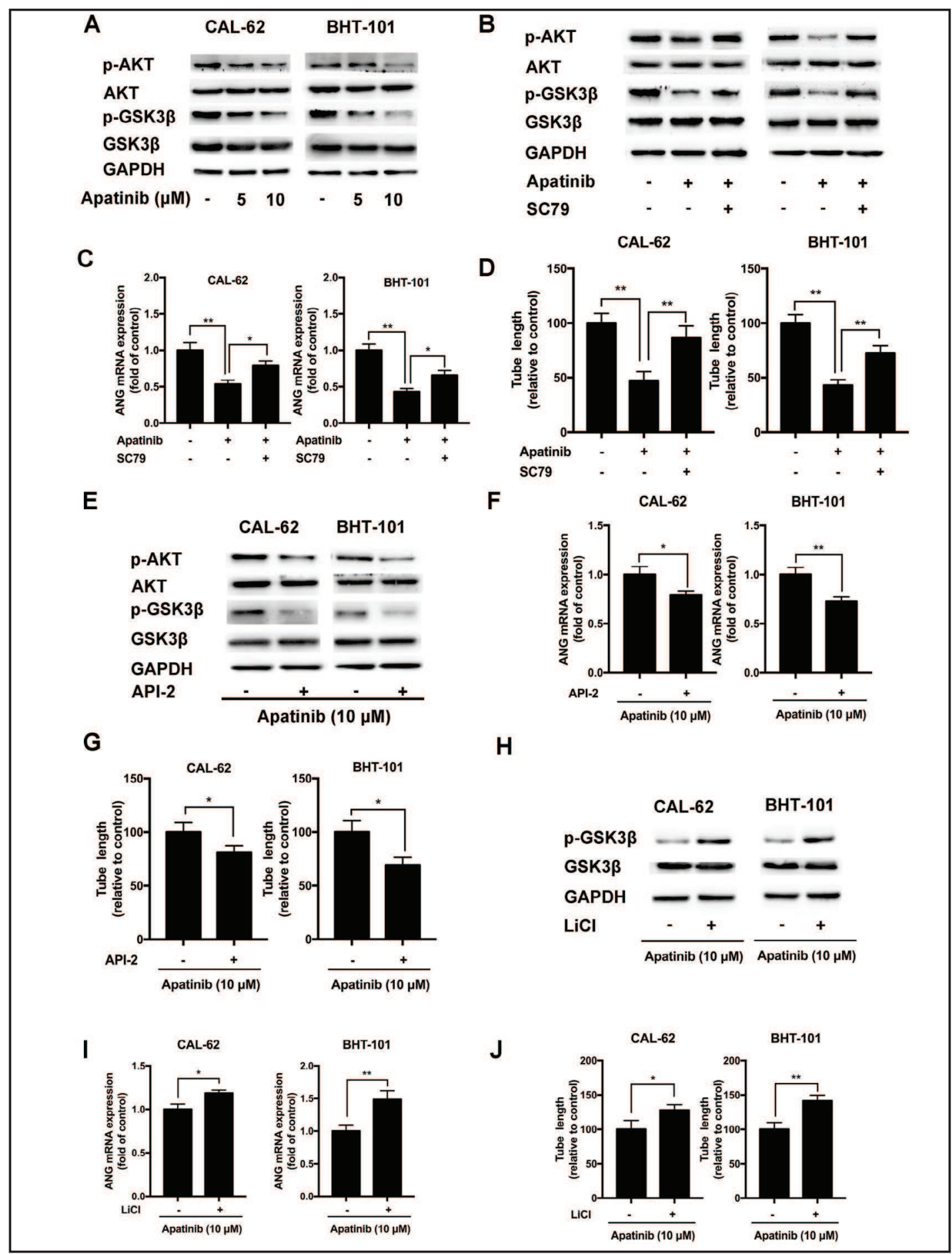

Fig. 5. Apatinib decreases ANG expression and angiogenesis via the AKT/GSK3 $\beta$ signaling pathway. (A) The expression of total and phosphorylated AKT and GSK3 $\beta$ in CAL-62 and BTH-101 cells with or without Apatinib treatment for $24 \mathrm{~h}$. CAL-62 and BHT-101 cells were treated with Apatinib $(10 \mu \mathrm{M})$ or together with SC79 $(4 \mu \mathrm{g} / \mathrm{ml})$ or API-2 $(2 \mu \mathrm{M})$ or $\mathrm{LiCl}(5 \mathrm{mM})$ up to $24 \mathrm{~h}$. (B, E and H) Cells were lysed and subjected to immunoblotting with the indicated antibodies. (C, F and I) The level of ANG was measured by qPCR. (D, G and J) Tube formation activity was detected and the relative tube length was shown as a bar chart. Data are represented as mean \pm SD of three independent experiments. ${ }^{*} \mathrm{p}<0.05 ;{ }^{* *} \mathrm{p}<0.01$. 


\section{Cellular Physiology Cell Physiol Biochem 2017;44:1471-1484 \begin{tabular}{l|l|l|}
\hline DOI: $10.1159 / 000485583$ & 2017 The Author(s). Published by S. Karger AG, Basel
\end{tabular} Published online: Dezember 01, 2017 www.karger.com/cpb}

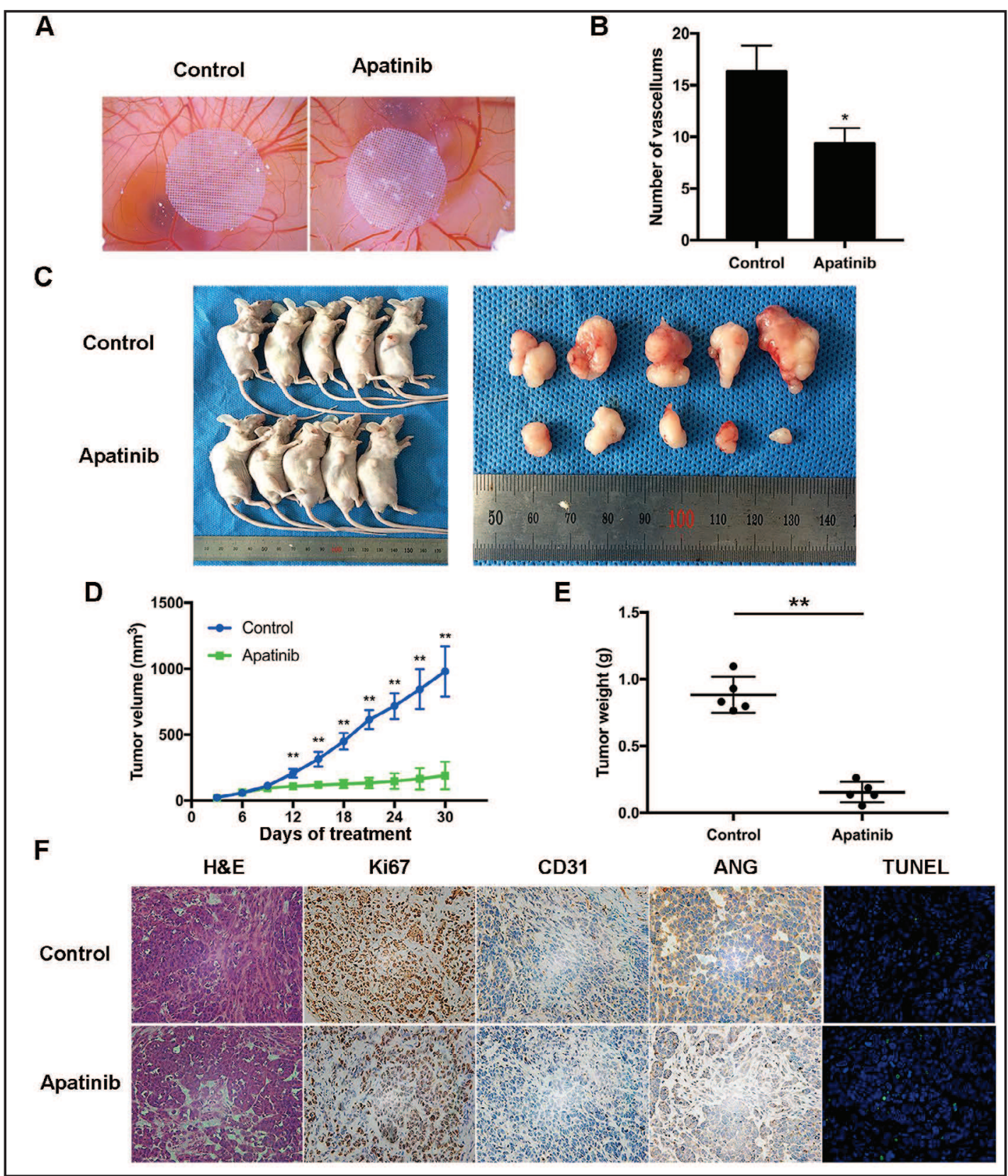

Fig. 6. Apatinib inhibits tumor growth and angiogenesis in vivo. (A) A chick embryo chorioallantoic membrane assay was used to observe the effects of Apatinib on angiogenesis. (B) The number of blood vessels surrounding the filter paper disc was assessed. Each bar represents the mean \pm SD from three independent experiments. (C) A representative tumor of xenograft mice injected with $5 \times 10^{6}$ CAL-62 cells. The mice were given by gavage once three days for 4 weeks with Apatinib or CMC. (D) Tumor volumes were measured every 3 days. (E) The weights of tumors in nude mice. (F) Representative images of TUNEL assay and IHC staining of Ki-67, CD31 and ANG were performed on serial sections of tumors from control groups and Apatinib group. ${ }^{*} \mathrm{p}<0.05,{ }^{* *} \mathrm{p}<0.01$.

Apatinib inhibits tumor growth and angiogenesis in vivo

Based on the results above, a traditional chick embryo chorioallantoic membrane (CAM) assay was used for observing the effects of Apatinib on angiogenesis. The vessel numbers treated with CAL-62/Apatinib $(10 \mu \mathrm{M})$ supernatant were significantly reduced, compared 


\section{Cellular Physiology Cell Physiol Biochem 2017:44:1471-1484

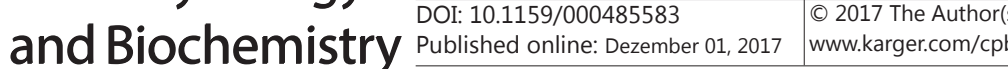 \\ Jin et al.: Apatinib Inhibits Angiogenesis in Anaplastic Thyroid Cancer}

with control groups $(16.33 \pm 2.52$ vs $9.33 \pm 1.53, P<0.05$; Fig. $6 \mathrm{~A}$ and $6 \mathrm{~B})$. Then, tumor xenograft mouse model was utilized to further confirm the effects of Apatinib. CAL-62 cells were subcutaneously injected into the right flank of athymic nude mice (Fig. 6C). As expected, the xenografts grew significantly slower in Apatinib group than those in the control group $\left(189.03 \pm 105.36 \mathrm{~mm}^{3}\right.$ vs. $989.88 \pm 191.92 \mathrm{~mm}^{3}, \mathrm{p}<0.01$; Fig. $6 \mathrm{D}$ and $\left.6 \mathrm{E}\right)$. The average tumor weight of xenografts was also lighter $(0.154 \pm 0.077 \mathrm{~g}$ vs. $0.884 \pm 0.134 \mathrm{~g}, \mathrm{p}<0.01$; Fig. 6D and 6E). The expressions of Ki-67, CD31 and ANG in xenografts were detected by IHC, and cell apoptosis were assayed by TUNEL (Fig. 6F). The expressions of Ki-67, CD31 and ANG were significantly reduced in Apatinib group compared to control group. Moreover, Apatinib treatment led to an increase in the number of apoptotic cells suggested by TUNEL assay. Thus, Apatinib could reduce tumor growth, repress ANG expression and inhibit angiogenesis in a xenograft model of ATC.

\section{Discussion}

Although ATC is a rather rare malignant tumor, it is notorious for its high levels of metastasis and poor prognosis [3]. Traditional treatment methods are mostly palliative, and adjuvant chemotherapy may prolong survival somewhat and improve quality of life. Several clinical trials have proven that Apatinib, a selective VEGFR2 inhibitor, is an effective drug in terminal gastric cancer, non-small-cell lung cancer (NSCLC) and breast cancer [20-22]. In this study, Apatinib was shown to exert a cytostatic effect on ATC cell lines via inducing cell apoptosis in vitro and in vivo. Liu et al [23]. reported that Apatinib could promote autophagy and apoptosis through VEGFR2/STAT3/BCL-2 signaling in osteosarcoma, and Peng et al [24]. indicated that Apatinib could inhibit VEGF signaling and promote apoptosis in intrahepatic cholangiocarcinoma.

Angiogenesis is a key step in cancer metastasis, promoting cancer progression via synthesis of new blood vessels [25-27]. ATC is prone to hematogenous metastasis to the lung and bone, and anti-angiogenesis is one of the leading mechanisms for Apatinib in tumor therapy [9, 28-30]. In our study, evidenced by HUVEC migration and tube formation assay, Apatinib could effectively inhibit angiogenesis in ATC in vitro. CAM assay and detection of CD31 expression in xenografts demonstrated similar effects in vivo. Our results suggested Apatinib could efficiently reduce angiogenesis in ATC and could be a potential therapeutic approach in ATC. Apatinib could inhibit angiogenesis by interfering with VEGF signaling [31]. However, in addition to the inhibition of VEGF signaling network, multiple regulation pathways may be involved in the anti-angiogenic effects of Apatinib.

Based on our pioneering research in ATC, antibody array and Western blot analyses showed that ANG was closely related to ATC and could be inhibited by Apatinib treatment. High serum levels of ANG were also observed in patients with divergent cancers, including breast cancer [32], bladder carcinoma [33], melanoma [34], B non-Hodgkin lymphoma [35], and prostate cancer [36]. As an essential factor in several stages of angiogenesis in malignant carcinoma, ANG can translocate rapidly to the nucleus and cleave tRNA, which promotes endothelial cell activities including migration, proliferation, and tube formation [8, 37, 38]. In our study, ANG could attenuate the anti-angiogenic effects of Apatinib, further confirming the anti-angiogenesis effects of Apatinib through reducing ANG expression. What's more, the comprehensive regulatory mechanisms of how Apatinib inhibited ANG level should be elaborated.

The Akt signaling pathway is one of the major survival gateways of tumor cells, and its expression rate is frequently high in many cases of carcinoma [39]. Increasing reports suggest that the dysregulation of this pathway has been involved in several pathological processes, including tumorigenesis, proliferation, invasion, cell cycle, apoptosis, angiogenesis, metastasis and drug resistance [40]. Our results showed that the level of p-Akt was decreased after Apatinib treatment. Through utilizing the activator SC79 of Akt and the inhibitor API-2 of Akt, we confirmed that Akt signaling was involved in the anti-angiogenic 


\section{Cellular Physiology Cell Physiol Biochem 2017;44:1471-1484 \begin{tabular}{l|l|l}
\cline { 2 - 3 } & DOI: 10.1159/000485583 & (C) 2017 The Author(s). Published by S. Karger AG, Base
\end{tabular} and Biochemistry Published online: Dezember 01, 2017 www.karger.com/cpb \\ Jin et al.: Apatinib Inhibits Angiogenesis in Anaplastic Thyroid Cancer}

effects of Apatinib. The Akt signaling pathway may closely interact with mTOR, VEGF and PDGF to influence angiogenesis [19].

GSK3 $\beta$, a serine/threonine kinase, is another downstream effector of Akt. It can be phosphorylated and deactivated by Akt [40]. GSK3 $\beta$ is also a nodal point of convergent signaling pathways in regulating angiogenesis $[41,42]$. In this study, in addition to Akt, p-GSK3 $\beta$ were reduced by Apatinib administration as well. The inhibitor LiCl of GSK3 $\beta$ could restore the anti-angiogenic effects of Apatinib. Previous studies have shown that the Akt/GSK3 $\beta$ signaling pathway could regulate cyclin D1, AM or other downstream targets to promote angiogenesis $[43,44]$. Our study found that ANG may be a downstream target of Akt/GSK3 $\beta$ signaling pathway. Activation of the Akt/GSK3 $\beta$ signaling pathway increased ANG expression, and this effect could be inhibited by Apatinib treatment.

In summary, our study demonstrates that Apatinib could inhibit ATC cells proliferation in a dose- and time- dependent manner through inducing apoptosis and blocking cell cycle. Suppression of AKT/GSK3 $\beta / A N G$ signaling pathway is involved in the anti-angiogenic effects of Apatinib. Our research may establish a novel strategy in ATC treatment and Apatinib is a potential therapeutic agent.

\section{Abbreviations}

ATC (anaplastic thyroid cancer); ANG (angiogenin); TKI (tyrosine kinase inhibitor); VEGFR-2 (vascular endothelial growth factor receptor-2); RET (rearranged during transfection); PDGFR- $\beta$ (platelet-derived growth factor- $\beta$ ); $c$-Kit (stem cell factor receptor); $\mathrm{c}$-Src (v-Src sarcoma viral oncogene homolog); CAM (chick embryo chorioallantoic membrane).

\section{Disclosure Statement}

The authors declare no conflicts of interest.

\section{Acknowledgements}

This study was supported by National Natural Science Foundation of China (81772558), Ph.D. Innovation Fund of Shanghai Jiaotong University School of Medicine (BXJ201709) and Shanghai Charitable Cancer Research Foundation.

\section{References}

1 Cabanillas ME, Zafereo M, Gunn GB, Ferrarotto R: Anaplastic Thyroid Carcinoma: Treatment in the Age of Molecular Targeted Therapy. J Oncol Pract 2016;12:511-518.

2 Haghpanah V, Fallah P, Tavakoli R, Naderi M, Samimi H, Soleimani M, Larijani B: Antisense-miR-21 enhances differentiation/apoptosis and reduces cancer stemness state on anaplastic thyroid cancer. Tumour Biol 2016;37:1299-1308.

-3 Perri F, Lorenzo GD, Scarpati GD, Buonerba C: Anaplastic thyroid carcinoma: A comprehensive review of current and future therapeutic options. World J Clin Oncol 2011;2:150-157.

4 Smallridge RC, Copland JA: Anaplastic thyroid carcinoma: pathogenesis and emerging therapies. Clin Oncol (R Coll Radiol) 2010;22:486-497.

5 Shimaoka K, Schoenfeld DA, DeWys WD, Creech RH, DeConti R: A randomized trial of doxorubicin versus doxorubicin plus cisplatin in patients with advanced thyroid carcinoma. Cancer 1985;56:2155-2160.

6 Folkman J, Klagsbrun M: Angiogenic factors. Science 1987;235:442-447. 


\section{Cellular Physiology Cell Physiol Biochem 2017;44:1471-1484 \begin{tabular}{ll|l} 
DOI: 10.1159/000485583 & $\begin{array}{l}\text { () } 2017 \text { The Author(s). Published by S. Karger AG, Basel } \\
\text { www.karger.com/cpb }\end{array}$
\end{tabular}}

Jin et al.: Apatinib Inhibits Angiogenesis in Anaplastic Thyroid Cancer

7 Fett JW, Strydom DJ, Lobb RR, Alderman EM, Bethune JL, Riordan JF, Vallee BL: Isolation and characterization of angiogenin, an angiogenic protein from human carcinoma cells. Biochemistry 1985;24:5480-5486.

8 Tsuji T, Sun Y, Kishimoto K, Olson KA, Liu S, Hirukawa S, Hu GF: Angiogenin is translocated to the nucleus of HeLa cells and is involved in ribosomal RNA transcription and cell proliferation. Cancer Res 2005;65:13521360.

-9eng R, Li J: Apatinib for the treatment of gastric cancer. Expert Opin Pharmacother 2015;16:117-122.

10 Hicklin DJ, Ellis LM: Role of the vascular endothelial growth factor pathway in tumor growth and angiogenesis. J Clin Oncol 2005;23:1011-1027.

11 Baldini E, Tuccilli C, Prinzi N, Sorrenti S, Antonelli A, Gnessi L, Morrone S, Moretti C, Bononi M, ArlotBonnemains Y, D'Armiento M, Ulisse S: Effects of selective inhibitors of Aurora kinases on anaplastic thyroid carcinoma cell lines. Endocr Relat Cancer 2014;21:797-811.

12 Broecker-Preuss M, Muller S, Britten M, Worm K, Schmid KW, Mann K, Fuhrer D: Sorafenib inhibits intracellular signaling pathways and induces cell cycle arrest and cell death in thyroid carcinoma cells irrespective of histological origin or BRAF mutational status. BMC Cancer 2015;15:184.

13 Murakawa T, Tsuda H, Tanimoto T, Tanabe T, Kitahara S, Matsubara O: Expression of KIT, EGFR, HER-2 and tyrosine phosphorylation in undifferentiated thyroid carcinoma: implication for a new therapeutic approach. Pathol Int 2005;55:757-765.

14 Cheng X, Wang B, Jin Z, Ma D, Yang W, Zhao R, Jing X, Shen B, Peng C, Qiu W: Pseudomonas aeruginosamannose-sensitive hemagglutinin inhibits pancreatic cancer cell proliferation and induces apoptosis via the EGFR pathway and caspase signaling. Oncotarget 2016;7:77916-77925.

15 Li K, Shen B, Cheng X, Ma D, Jing X, Liu X, Yang W, Peng C, Qiu W: Phenotypic and Signaling Consequences of a Novel Aberrantly Spliced Transcript FGF Receptor-3 in Hepatocellular Carcinoma. Cancer Res 2016;76:4205-4215.

16 Ma D, Jing X, Shen B, Liu X, Cheng X, Wang B, Fu Z, Peng C, Qiu W: Leukemia inhibitory factor receptor negatively regulates the metastasis of pancreatic cancer cells in vitro and in vivo. Oncol Rep 2016;36:827836.

17 Mottet D, Dumont V, Deccache Y, Demazy C, Ninane N, Raes M, Michiels C: Regulation of hypoxia-inducible factor-1alpha protein level during hypoxic conditions by the phosphatidylinositol 3-kinase/Akt/glycogen synthase kinase 3beta pathway in HepG2 cells. J Biol Chem 2003;278:31277-31285.

-18 Skuli N, Monferran S, Delmas C, Lajoie-Mazenc I, Favre G, Toulas C, Cohen-Jonathan-Moyal E: Activation of RhoB by hypoxia controls hypoxia-inducible factor-1alpha stabilization through glycogen synthase kinase-3 in U87 glioblastoma cells. Cancer Res 2006;66:482-489.

19 Safdari Y, Khalili M, Ebrahimzadeh MA, Yazdani Y, Farajnia S: Natural inhibitors of PI3K/AKT signaling in breast cancer: emphasis on newly-discovered molecular mechanisms of action. Pharmacol Res 2015;93:110.

-20 Li J, Qin S, Xu J, Xiong J, Wu C, Bai Y, Liu W, Tong J, Liu Y, Xu R, Wang Z, Wang Q, Ouyang X, Yang Y, Ba Y, Liang J, Lin X, Luo D, Zheng R, Wang X, Sun G, Wang L, Zheng L, Guo H, Wu J, Xu N, Yang J, Zhang H, Cheng Y, Wang N, Chen L, Fan Z, Sun P, Yu H: Randomized, Double-Blind, Placebo-Controlled Phase III Trial of Apatinib in Patients With Chemotherapy-Refractory Advanced or Metastatic Adenocarcinoma of the Stomach or Gastroesophageal Junction. J Clin Oncol 2016;34:1448-1454.

-21 Song Z, Yu X, Lou G, Shi X, Zhang Y: Salvage treatment with apatinib for advanced non-small-cell lung cancer. Onco Targets Ther 2017;10:1821-1825.

22 Hu X, Cao J, Hu W, Wu C, Pan Y, Cai L, Tong Z, Wang S, Li J, Wang Z, Wang B, Chen X, Yu H: Multicenter phase II study of apatinib in non-triple-negative metastatic breast cancer. BMC Cancer 2014;14:820.

23 Liu K, Ren T, Huang Y, Sun K, Bao X, Wang S, Zheng B, Guo W: Apatinib promotes autophagy and apoptosis through VEGFR2/STAT3/BCL-2 signaling in osteosarcoma. Cell Death Dis 2017;8:e3015.

24 Peng H, Zhang Q, Li J, Zhang N, Hua Y, Xu L, Deng Y, Lai J, Peng Z, Peng B, Chen M, Peng S, Kuang M: Apatinib inhibits VEGF signaling and promotes apoptosis in intrahepatic cholangiocarcinoma. Oncotarget 2016;7:17220-17229.

-25 Folkman J: Angiogenesis. Annu Rev Med 2006;57:1-18.

26 Chen W, Zhou H, Ye L, Zhan B: Overexpression of SULT2B1b Promotes Angiogenesis in Human Gastric Cancer. Cell Physiol Biochem 2016;38:1040-1054. 


\section{Cellular Physiology Cell Physiol Biochem 2017;44:1471-1484 \begin{tabular}{l|l|l} 
DOI: 10.1159/000485583 & ( ) 2017 The Author(s). Published by S. Karger AG, Basel
\end{tabular} and Biochemistry Published online: Dezember 01, 2017 www.karger.com/cpb}

Jin et al.: Apatinib Inhibits Angiogenesis in Anaplastic Thyroid Cancer

27 Meng F, Chen X, Song H, Lou G: LAPTM4B down regulation inhibits the proliferation, invasion and angiogenesis of HeLa cells in vitro. Cell Physiol Biochem 2015;37:890-900.

-28 Kim KL, Suh W: Apatinib, an Inhibitor of Vascular Endothelial Growth Factor Receptor 2, Suppresses Pathologic Ocular Neovascularization in Mice. Invest Ophthalmol Vis Sci 2017;58:3592-3599.

-29 Iman V, Karimian H, Mohan S, Hobani YH, Noordin MI, Mustafa MR, Noor SM: In vitro and in vivo antiangiogenic activity of girinimbine isolated from Murraya koenigii. Drug Des Devel Ther 2015;9:1281-1292.

-30 Ribatti D: Tumor refractoriness to anti-VEGF therapy. Oncotarget 2016;7:46668-46677.

-31 Tian S, Quan H, Xie C, Guo H, Lu F, Xu Y, Li J, Lou L: YN968D1 is a novel and selective inhibitor of vascular endothelial growth factor receptor-2 tyrosine kinase with potent activity in vitro and in vivo. Cancer Sci 2011;102:1374-1380.

-32 He T, Qi F, Jia L, Wang S, Wang C, Song N, Fu Y, Li L, Luo Y: Tumor cell-secreted angiogenin induces angiogenic activity of endothelial cells by suppressing miR-542-3p. Cancer Lett 2015;368:115-125.

-33 Zhao H, Grossman HB, Delclos GL, Hwang LY, Troisi CL, Chamberlain RM, Chenoweth MA, Zhang H, Spitz $\mathrm{MR}, \mathrm{Wu} \mathrm{X}$ : Increased plasma levels of angiogenin and the risk of bladder carcinoma: from initiation ot recurrence. Cancer 2005;104:30-35.

-34 Vihinen P, Kallioinen M, Vuoristo MS, Ivaska J, Syrjanen KJ, Hahka-Kemppinen M, Kellokumpu-Lehtinen PL, Pyrhonen SO: Serum angiogenin levels predict treatment response in patients with stage IV melanoma. Clin Exp Metastasis 2007;24:567-574.

-35 Passam FH, Sfiridaki A, Pappa C, Kyriakou D, Petreli E, Roussou PA, Alexandrakis MG: Angiogenesis-related growth factors and cytokines in the serum of patients with B non-Hodgkin lymphoma; relation to clinical features and response to treatment. Int J Lab Hematol 2008;30:17-25.

-36 Pina F, Botelho F, Lopes T, Lopes I, Figueiredo G, Portugal R, Ferro A, Cruz F, Barros H, Lunet N: Can serum angiogenin be used to improve the diagnostic performance in prostate cancer screening? Eur J Cancer Prev 2014;23:166-172.

37 Gao X, Xu Z: Mechanisms of action of angiogenin. Acta Biochim Biophys Sin (Shanghai) 2008;40:619-624.

-38 Zhu J, Sheng J, Dong H, Kang L, Ang J, Xu Z: Phospholipid scramblase 1 functionally interacts with angiogenin and regulates angiogenin-enhanced rRNA transcription. Cell Physiol Biochem 2013;32:16951706.

-39 Liu P, Cheng H, Roberts TM, Zhao JJ: Targeting the phosphoinositide 3-kinase pathway in cancer. Nat Rev Drug Discov 2009;8:627-644.

40 Zhang J, Yu XH, Yan YG, Wang C, Wang WJ: PI3K/Akt signaling in osteosarcoma. Clin Chim Acta 2015;444:182-192.

-41 Kim HS, Skurk C, Thomas SR, Bialik A, Suhara T, Kureishi Y, Birnbaum M, Keaney JF, Jr., Walsh K: Regulation of angiogenesis by glycogen synthase kinase-3beta. J Biol Chem 2002;277:41888-41896.

\$2 Zhao P, Li Q Shi Z, Li C, Wang L, Liu X, Jiang C, Qian X, You Y, Liu N, Liu LZ, Ding L, Jiang BH: GSK-3beta regulates tumor growth and angiogenesis in human glioma cells. Oncotarget 2015;6:31901-31915.

43 Wang CY, Tsai AC, Peng CY, Chang YL, Lee KH, Teng CM, Pan SL: Dehydrocostuslactone suppresses angiogenesis in vitro and in vivo through inhibition of Akt/GSK-3beta and mTOR signaling pathways. PLoS One 2012;7:e31195.

44 Chen Y, Li C, Xie H, Fan Y, Yang Z, Ma J, He D, Li L: Infiltrating mast cells promote renal cell carcinoma angiogenesis by modulating PI3K-->AKT-->GSK3beta-->AM signaling. Oncogene 2017;36:2879-2888. 